\title{
An improved system for estradiol-dependent regulation of gene expression in yeast
}

\author{
María J Quintero1, Douglas Maya1, Miguel Arévalo-Rodríguez², \\ Ángel Cebolla ${ }^{2}$ and Sebastián Chávez*1
}

Address: ${ }^{1}$ Departamento de Genética, Universidad de Sevilla, Avda. Reina Mercedes 6, E41012-Seville, Spain and 2Biomedal, SL, E41092-Seville, Spain

Email: María J Quintero - mjoseqc@us.es; Douglas Maya - doumaymil@alum.us.es; Miguel Arévalo-Rodríguez - miguel.arevalo@biomedal.com; Ángel Cebolla - acebolla@biomedal.com; Sebastián Chávez* - schavez@us.es

* Corresponding author

Published: 20 March 2007

Microbial Cell Factories 2007, 6:10 doi:10.1 186/1475-2859-6-10
Received: 6 November 2006

Accepted: 20 March 2007

This article is available from: http://www.microbialcellfactories.com/content/6/1/10

(c) 2007 Quintero et al; licensee BioMed Central Ltd.

This is an Open Access article distributed under the terms of the Creative Commons Attribution License (http://creativecommons.org/licenses/by/2.0), which permits unrestricted use, distribution, and reproduction in any medium, provided the original work is properly cited.

\begin{abstract}
Background: Saccharomyces cerevisiae is widely utilized in basic research as a model eukaryotic organism and in biotechnology as a host for heterologous protein production. Both activities demand the use of highly regulated systems, able to provide accurate control of gene expression in functional analysis, and timely recombinant protein synthesis during fermentative production. The tightly regulated GAL I- 10 promoter is commonly used. However, induction of the GAL system requires the presence of the rather expensive inducer galactose and the absence of glucose in the culture media. An alternative to regulate transcription driven by GAL promoters, free of general metabolic changes, is the incorporation of the hybrid Gal4-ER-VPI6 protein developed by D. Picard. This chimeric protein provides galactose-independent activation of transcription from GAL promoters in response to $\beta$-estradiol, even in the presence of glucose. However, constitutive expression of this transactivator results in relatively high basal activity of the GAL promoters, therefore limiting the gene expression capacity that is required for a number of applications.

Results: In order to improve this expression tool, we have introduced additional regulatory elements allowing a simultaneous control of both the abundance and the intrinsic activity of the Gal4-ER-VPI6 chimeric transactivator. The most efficient combination was obtained by placing the coding sequence of the hybrid activator under the control of the GALI promoter. This configuration results in an amplification feedback loop that is triggered by the hormone, and ultimately leads to the enhanced regulation of recombinant genes when these are also driven by a GALI promoter. The basal expression level of this system is as low as that of native GAL-driven genes in glucose-containing media.
\end{abstract}

Conclusion: The feedback regulatory loop that we have engineered allows a 250 -fold induction of the regulated gene, without increasing the basal activity of the target promoter, and achieving a I2-fold higher regulation efficiency than the previous configuration. 


\section{Background}

Recombinant DNA expression constitutes a major approach in gene function studies that naturally complement genetic and genomic research. Well-regulated expression systems provide an invaluable tool to investigate the cellular roles of novel genes, either in their original cellular environment, or in specialized host organisms. Thus, these systems can be utilized to observe the biological effects of the controlled expression (or lack of it) of a given DNA sequence. Very often they also provide the means to produce and purify a desired gene product, opening the way to the comprehensive analysis and manufacture of proteins of biotechnological interest.

S. cerevisiae has been widely employed as a host organism in the expression of heterologous proteins [1-7], using regulated systems developed to allow low basal, highly inducible protein production. In this sense, timely expression during fermentation is important to prevent a premature metabolic burden and any possible toxic effect throughout the culture growing-phase that might lead to a reduction in protein yields, or to genetic instability. Yeast-derived transcriptional promoters used in the above mentioned systems are, along with others, those of the MET3 gene, negatively regulated by the amino acid methionine [8], the PHO5 gene, negatively regulated by inorganic phosphate [9], the CUP1 gene, activated by $\mathrm{Cu}^{2+}$ ions [10], and the GAL1 and GAL10 genes, activated by galactose and repressed by glucose $[11,12]$. Other yeast systems designed for tightly regulated gene expression incorporate transcriptional elements derived from bacteria, like those inducible or repressible by tetracycline (TetOff and Tet-On) $[13,14]$.

Expression systems based on the GAL1-10 promoter are among the strongest ones [15]. Under natural conditions, expression of the GAL1 and GAL10 genes depends on the product of the GAL4 gene, which activates the GAL1-10 promoter in the presence of galactose and the absence of glucose [16], a major disadvantage when the metabolic changes associated to this switch in carbon source are relevant to the study. In addition, the high cost of the inducer can preclude scaling up production of a commercially valuable protein using this system. A good alternative to regulate transcription driven by GAL promoters is the incorporation of the hybrid protein developed by $D$. Picard and co-workers, a chimerical transcriptional activator that combines the DNA binding domain of Gal4 with the hormone binding domain of human estrogen receptor and the transactivation domain of the herpex virus protein VP16 [17]. This system permits the $\beta$-estradiolinducible expression of recombinant genes placed under the control of GAL promoters, in a manner that is independent of the presence or absence of galactose or glucose. The system is virtually independent of media formulation and avoids undesired physiological changes associated with carbon source switch, but the constitutive expression of the chimeric transactivator produces increased basal activities of the target promoters. The reported effects of the transactivator on the basal activity of GAL promoters range between 2.3- [18] and 11.4-fold [17]. In this report we describe an improved yeast expression platform based on the system described by Louvion et al [17]. This improvement relies on linked regulatory cascades or positive feedback loops that amplify the activating signal of the inducer molecule. Both the cascade and the loop modulate simultaneously the abundance of the transactivator and its intrinsic activity, resulting in low-basal, highly inducible gene expression systems.

\section{Results and Discussion \\ A native GAL promoter does not eliminate the basal increase produced by Gal4-ER-VPI6}

In order to explore possible ways to improve the efficiency of the yeast estrogen-regulated system described by Louvion et al [17], we first tested if the high basal activity levels reported by these authors were due to the use of artificial GAL promoters, combining a number of Gal UAS fused to the CYC1 TATA sequences. To this end, we measured the effect of a constitutive Gal4-ER-VP16 transactivator on the expression of a reporter gene (lacZ), placed under the control of a native GAL1 promoter, in the absence of $\beta$-estradiol. We found that the constitutive Gal4-ER-VP16 [17] produced a 13.3-fold increase in the activity of the native GAL1 promoter (Fig 1A). Addition of $\beta$-estradiol to the culture medium produced a further 32.4-fold increase in the activity of the native GAL1 promoter (Fig 1A), this induction being weaker than that reported by Louvion et al. for the artificial GAL promoters (between 100 and 200-fold) [17]. Therefore, a native GAL promoter would not improve the regulation capacity of an expression system based on the Gal4-ER-VP16 protein.

\section{An estradiol-induced transcriptional cascade}

We investigated the possibility of linking the Gal4-ERVP16-regulated system upstream to a second, $\beta$-estradioldependent expression system. As this second system we chose a GAL1 promoter-driven human estrogen receptor (ER) and a target reporter for this transactivator (ERElacZ), consisting of a minimal CYC1 promoter fused to three estrogen-responsive elements (ERE) and driving lacZ transcription. The combination of the GAL1pr-controlled ER with the constitutively expressed Gal4-ER-VP16 would produce a transcriptional cascade that should be active only in the presence of hormone. Its final activator (ER) is controlled by $\beta$-estradiol, at both its expression level and its transactivator activity (Fig 2A). As shown in Fig. 1B, in the presence of galactose the GAL1pr-ER/ERE-lacZ system alone showed very low activation when $1 \mu \mathrm{M} \beta$-estradiol was added (3.2-fold induction). This is a poor induction 
A

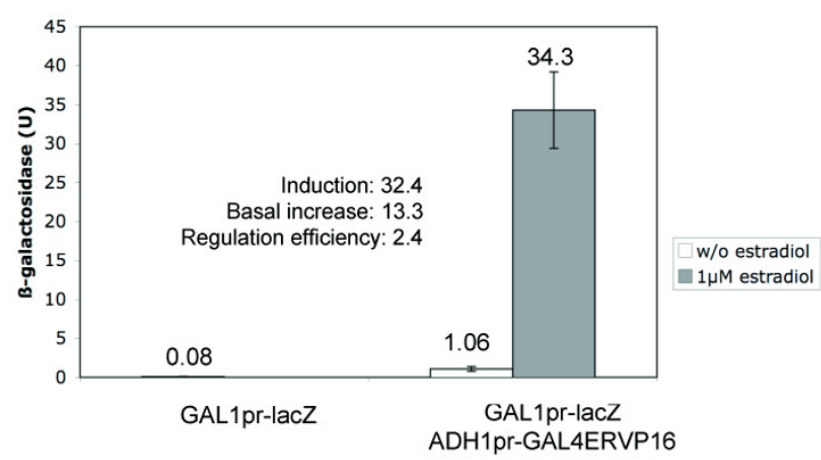

C

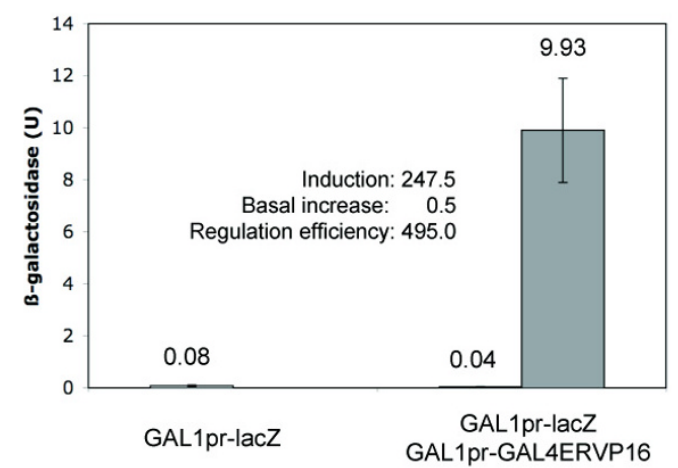

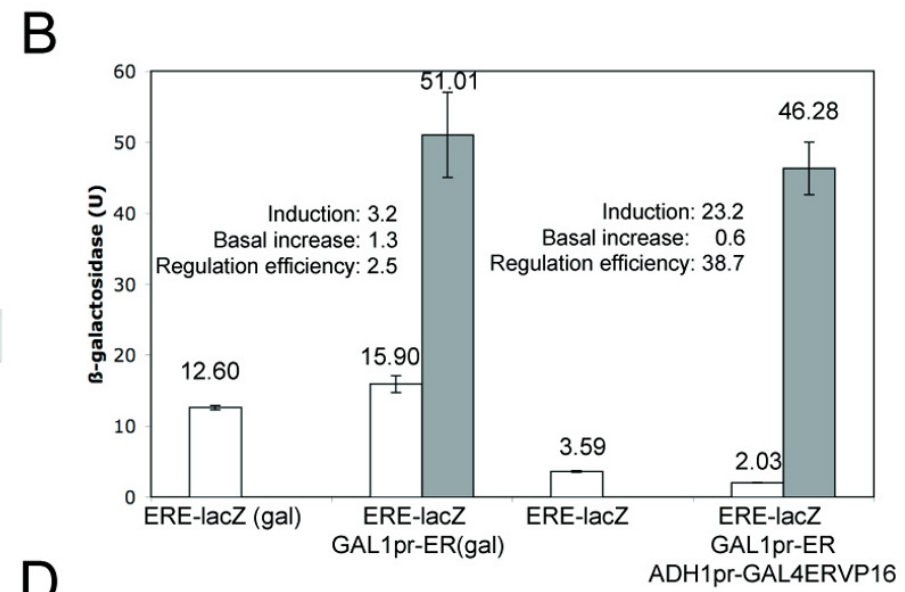

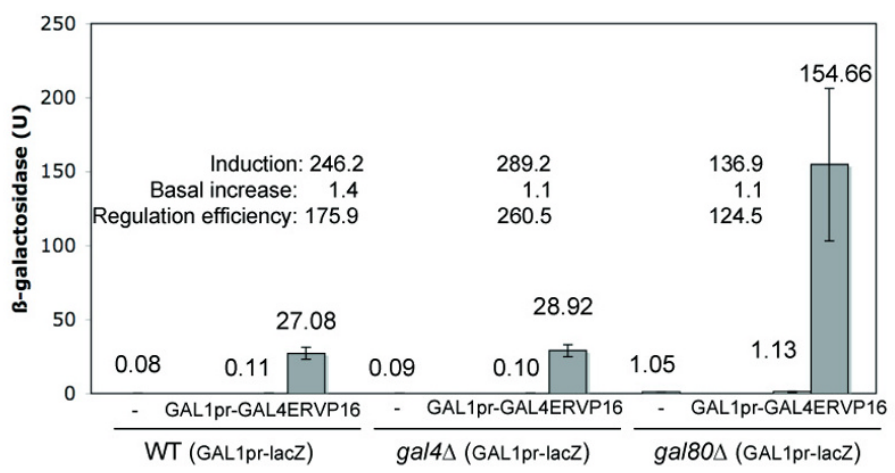

\section{Figure I}

Hormone-dependent regulation of $\beta$-galactosidase by the different systems analysed in this work. $\beta$-galactosidase activities (Miller units) of W303-IA (A, B, C) or BY474I (D) cells containing the following plasmids: (A) p4I6GALI-lacZ and pHCA/GAL4(I-93)ERVPI6; (B) pVitBx2 and pGALI-ER; or pVitBx2, pGALI-ER and pHCA/GAL4(I-93)ERVPI6; (C) p4I6GALI-lacZ and p4I4GALI-GAL4ERVPI6; (D) p4I6GALI-lacZ and p4I5GALI-GAL4ERVPI6. All cultures were grown in the presence of glucose except when "gal" is written, indicating galactose-containing cultures. In all cases, $5 \mathrm{ml}$ cultures were inoculated from a mid-log preculture to an O.D. $(600 \mathrm{~nm})$ of 0.02 , and incubated for 14 hours at $30^{\circ} \mathrm{C}$ in the presence or the absence of I $\mu \mathrm{M} \beta$-estradiol. Average and standard deviation of at least three independent experiments are represented. Induction represents the ratio between $\beta$-galactosidase activities (in the presence and in the absence of $\beta$-estradiol). Basal increase was calculated dividing the $\beta$-galactosidase activity detected in the absence of hormone, by the activity exhibited by cells cultured in the same conditions, containing the same target reporter construct, but lacking any estrogen-dependent transactivator. Regulation efficiency was calculated dividing induction by basal increase.

value, in comparison to previous studies of ER-dependent regulation in yeast [19-22], probably due to the high intrinsic activity of the ERE-lacZ reporter. However, combination of the GAL1pr-ER/ERE-lacZ system with the constitutively expressed Gal4-ER-VP16 in the "cascade-like" configuration resulted in a $\beta$-estradiol-inducible system with a reduced basal increase and an improved (23.2fold) induction level. The induction time courses of the combined ADH1pr-Gal4-ER-VP16/GAL1pr-ER/ERE-lacZ system in glucose plus $\beta$-estradiol and the GAL1pr-ER/ ERE-lacZ in galactose were similar (Fig 3A), indicating that the higher complexity of the cascade system does not involve a slower response. The cascade induction reached a plateau 10-12 hours after the addition of the hormone (Fig 3B).

The global efficiency of a regulated expression system depends on both the induction level and the increase in basal activity of the target promoter due to the presence of its associated activator. In order to compare the different systems tested we introduced a new parameter, called regulation efficiency, obtained as the ratio between the induction level and the increase in basal activity observed with each system. Thus, the system composed by the constitutively expressed ADH1pr-Gal4-ER-VP16 transactivator and the GAL1 promoter showed a regulation efficiency of 
A

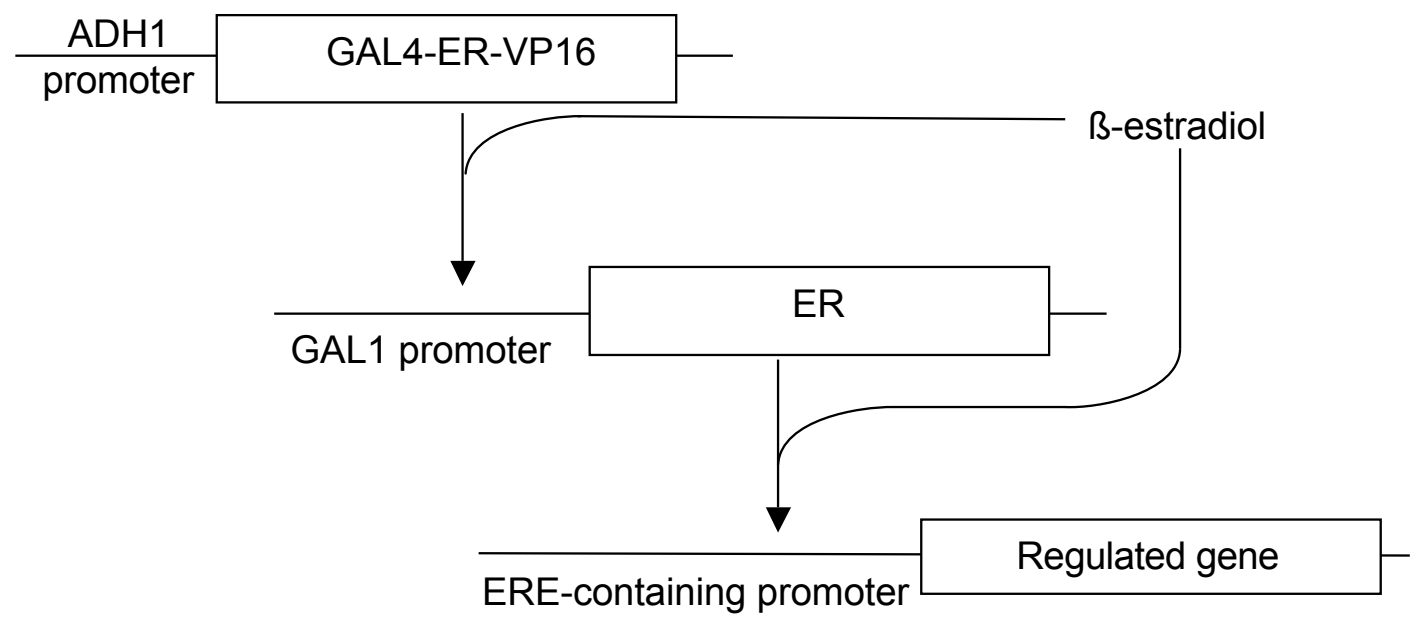

B

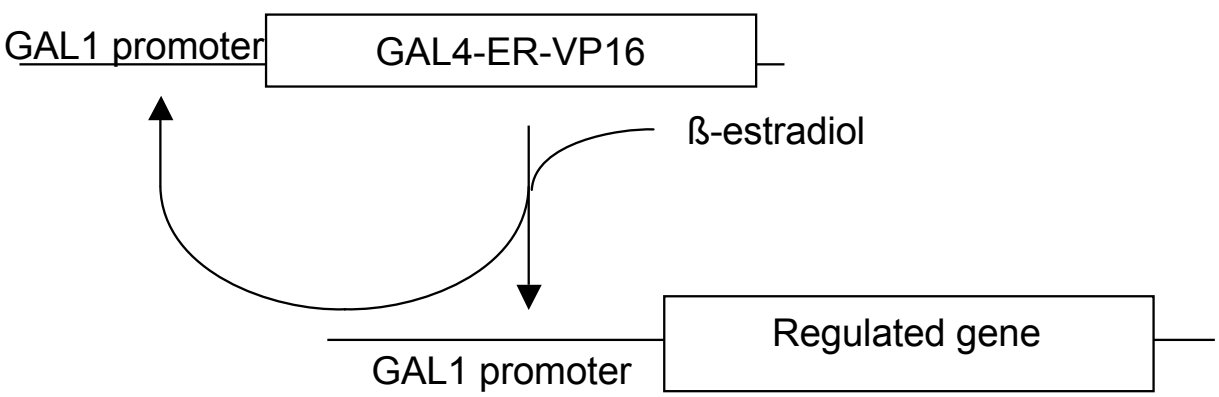

Figure 2

Synoptic explanation of the two estrogen-induced regulatory systems described in this work. A. $\beta$-estradiolinduced transcriptional cascade. B. $\beta$-estradiol-triggered self-induced regulatory loop. Boxes indicate coding regions; arrows indicate activation.

2.4. A similarly low value was exhibited by the GAL1prER/ERE-lacZ system for $\beta$-estradiol in the presence of galactose. In contrast, the ADH1pr-Gal4-ER-VP16/ GAL1pr-ER/ERE-lacZ system showed a regulation efficiency of 38.7, indicating that the sequential action of two regulators is more convenient when an accurate regulation is needed. This improved regulation resulted from the combination of a higher induction level (23.2-fold) with a slight reduction of the basal activity of the ERE-lac $Z$ reporter (0.6-fold). However, according to the values reported by Louvion et al., the regulation efficiency of their system ranged between 11.0 and 40.5 [17]. We therefore conclude that the transcriptional cascade assembled in these studies, although resulting in a moderately low basal activity of the target promoter, does not significantly improve the regulation efficiency of the original Gal4-ERVP16-dependent system.

\section{An estradiol-triggered self-induced regulatory loop}

As an alternative approach, and in order to prevent the increase in basal activity of GAL promoters produced by the constitutive expression of Gal4-ER-VP16, we placed the transcription of this chimeric transactivator under the control of a GAL1 promoter. The resulting system, designed as a self-inducible regulatory loop triggered by $\beta$ estradiol is depicted in Fig 2B. First, we measured the expression of a GAL1pr-lacZ reporter construct in cells containing this regulatory loop in the absence of estrogen, finding no increase in the basal activity of the GAL1 promoter, but rather a small decrease (Fig 1C). When these 

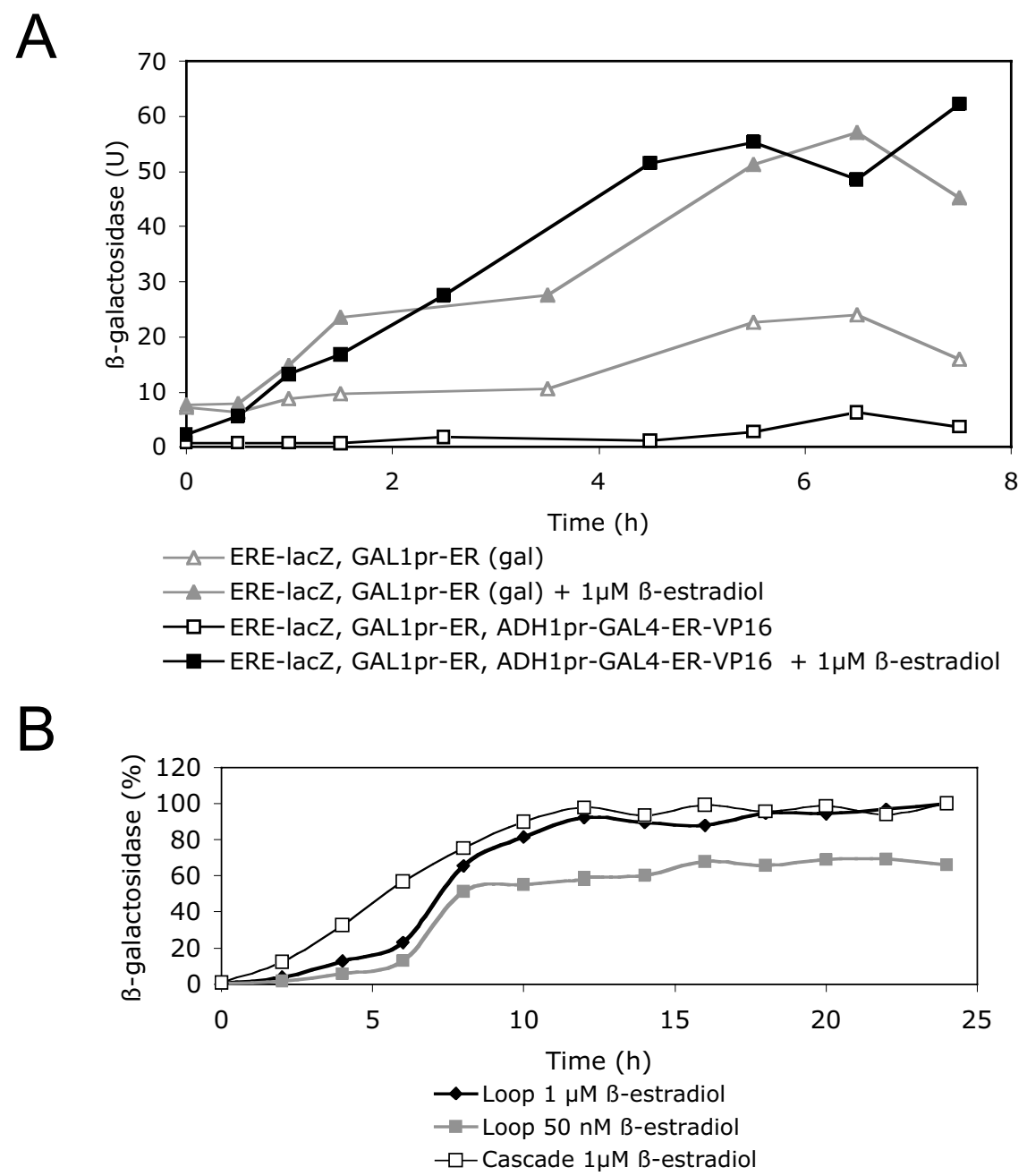

\section{Figure 3}

Induction time-course of the estrogen-dependent transcriptional cascade and of the estradiol-triggered regulatory loop. A. $25 \mathrm{ml}$ glucose selective medium were inoculated with W303-IA yeast cells, containing plasmids pVitBx2, pHCA/GAL4(I-93)ERVPI6 and pGALI-ER. A similar volume of galactose selective medium was inoculated with yeast cells containing plasmids pVitBx2 and pGALI-ER. After adding I $\mu M \beta$-estradiol (solved in ethanol), or similar amounts of ethanol, samples were taken at the indicated time points and assayed for $\beta$-galactosidase (Miller units). $A$ representative experiment is shown. B. 24 hours time-course of W303-IA yeast cells, containing the cascade system (plasmids pVitBx2, pHCA/GAL4(I93)ERVPI 6 and PGALI-ER) after adding I $\mu M \beta$-estradiol, compared with W303-IA yeast cells containing the loop system (plasmids p4I6GALI-lacZ and p4I4GALI-GAL4ERVPI6) after adding two different hormone conentration (I $\mu$ M and $50 \mathrm{nM}$ ). The experiments were performed as in $A$. To facilitate comparison, the results were represented as the percentage of the maximal values reached by each culture, except for the loop $50 \mathrm{nM}$ estradiol, wich was referred to the maximal value of the loop culture containing I $\mu \mathrm{M}$ estradiol. A representative experiment is shown.

cells were cultured in the presence of $1 \mu \mathrm{M} \beta$-estradiol, we measured a 247.5-fold induction of lacZ expression. Although the overall maximal activity was 3.5-fold higher when the activator was constitutively expressed (Fig $1 \mathrm{~A}, \mathrm{C})$, the induction of the loop exceeded the highest induction level reported by Louvion et al. [17] and it was 7 times higher than that produced by the constitutively expressed Gal4-ER-VP16 system on the same target promoter (Fig 1A).

Considering altogether the small reduction in basal activity and the considerable induction level observed, the resulting regulation efficiency of the self-inducing system was very high (495.0). Although the basal activities of the 
A

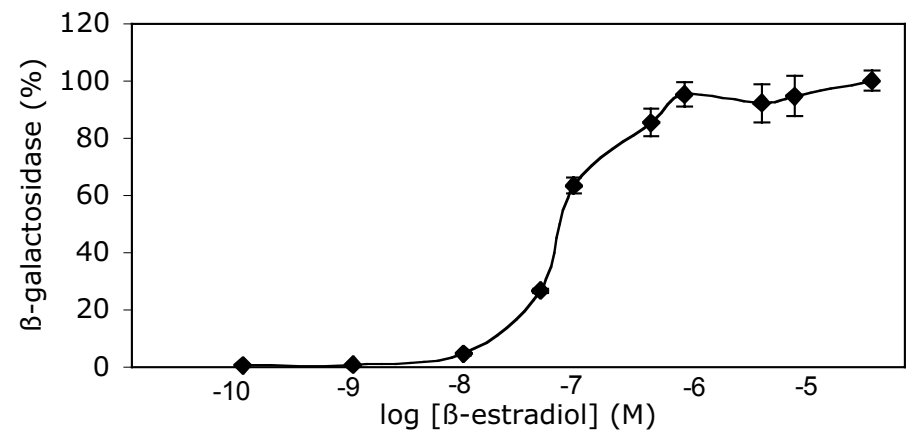

B

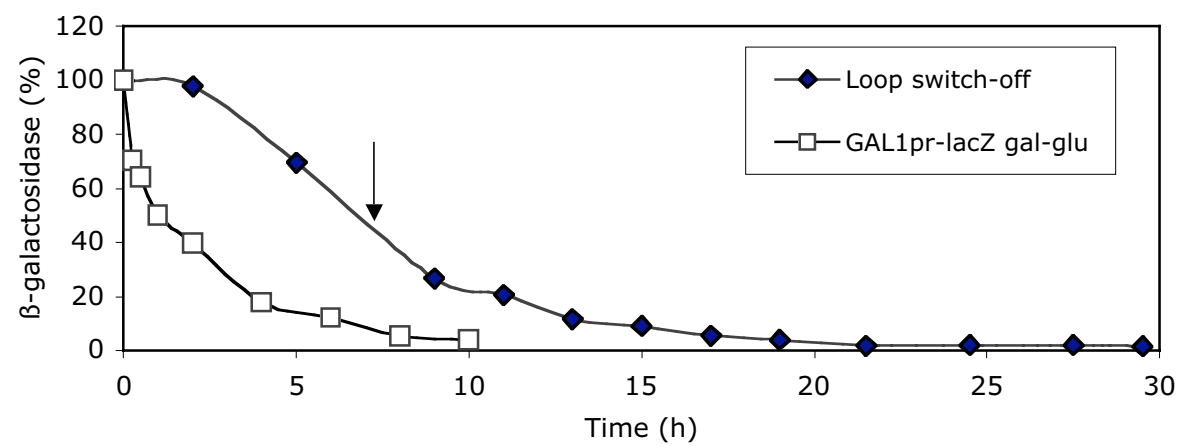

\section{Figure 4}

Hormone-dependence and switch-off time course of the $\beta$-estradiol-triggered self-induced regulatory loop. 5 $\mathrm{ml}$ glucose cultures of W303-I A cells containing plasmids p4 I6GALI-lacZ and p4 I4GALI-GAL4ERVPI 6 were inoculated as in Fig I and grown for 14 hours in the presence of the indicated concentration of $\beta$-estradiol and assayed for $\beta$-galactosidase. The average and standard deviation of three different experiments is represented. $\mathrm{B}$. $100 \mathrm{ml}$ glucose medium were inoculated with yeast cells containing plasmids p4I6GALI-lacZ and p4I4GALI-GAL4ERVPI6 and grown until stationary phase (I9 h) in the presence of $50 \mathrm{nM}$ estradiol. Cells were then washed three times by centrifugation and used to inoculate a new $100 \mathrm{ml}$ culture lacking $\beta$-estradiol, at a $\mathrm{OD}(600 \mathrm{~nm})$ of 0.2 . Seven hours later (arrow) cells were washed again and used to inoculate a new culture at a $\operatorname{OD}(600 \mathrm{~nm})$ of 0.2 . As a control, a $100 \mathrm{ml}$ glucose culture was inoculated at a $\mathrm{OD}(600 \mathrm{~nm})$ of 0.2 , from a saturated preculture grown in galactose. Samples were taken at the indicated times and assayed for $\beta$-galactosidase activity. A representative experiment is shown

loop system are close to zero, and therefore this number should be considered cautiously, it represents one order of magnitude higher than the values found for the constitutively expressed Gal4-ER-VP16 system or the transcriptional cascade described above. The tighter regulation of this loop system involved an exponential kinetic of induction rather than linear kinetic shown by the cascade system, as indicated by the induction time-courses shown in Fig 3B. However, both the cascade and the loop systems reached the maximal induction 10-12 hours after adding the hormone (Fig 3B).

The high efficiency of this regulatory loop is not restricted to the W303 yeast genetic background. When we introduced the GAL1pr-GAL4ERVP16/GAL1pr-lacZ system in an S288C-derivative strain (BY4741), similar induction levels (246-fold) and regulation efficiency (176) were obtained (Fig 1D). Moreover, in the S288C background the maximal activities were higher than in W303 (Fig 1C,D).

In order to characterize the loop system further, we investigated its dependence on Gal4 and Gal80, the two specific regulators of the GAL1 promoter. As shown in Fig 1D, the absence of the Gal4 activator did not affect significantly either the basal or the induced levels. In the absence of the Gal80 repressor, the basal activity of the GAL1 promoter was increased, as could be expected. Again the loop system caused a significant induction in this background (Fig 1D). These results suggest that the loop system can be 
Table I: Plasmids used in this work

\begin{tabular}{lll}
\hline Plasmid & Relevant features & Reference \\
\hline P4I6GALI-lacZ & URA3, CEN, GALIpr::lacZ & {$[26]$} \\
pHCA/GAL4(I-93)ERVPI6 & HIS3, CEN, ADHIpr::GAL4ERVPI6 & {$[17]$} \\
PVitBx2 & URA3, CEN, ERE-CYCI pr::lacZ & {$[30]$} \\
PGALI-ER & LEU2, CEN, GALIpr::ER & This study \\
P4I4GALI-GAL4ERVPI6 & TRPI, CEN,GALIpr::GAL4ERVPI6 & This study \\
P4I5GALI-GAL4ERVPI6 & LEU2, CEN,GALIpr::GAL4ERVPI6 & This study \\
PP6HEG0 & human ER & {$[25]$} \\
PRS4I5 & LEU2, CEN & {$[27]$} \\
P4I4GALI & TRPI, CEN, GALIpr & {$[26]$} \\
\hline
\end{tabular}

easily adapted to other eukaryotic cells lacking the Gal4 and Gal80 regulators.

We also measured the hormone dose-response of the loop system. The levels obtained after culturing the yeast cells with increasing concentrations of estradiol are shown in Fig 4A. Maximal induction was observed at about $1 \mu \mathrm{M}$ and the half-maximal response at $0.05 \mu \mathrm{M}$. These values are one order of magnitude higher than those reported for the constitutively expressed Gal4-ER-VP16 system [17] and for the hormone-dependence of ER in yeast $[19,21]$. In fact, the dose response of the loop system does not show the typical sharp increase of hormone receptors, suggesting that the self-induced loop facilitates to obtain intermediate levels of expression. Moreover, the time course of the induction at sub-optimal hormone concentration $(50 \mathrm{nM})$ also indicated an exponential kinetic, but at this ligand concentration the loop system reached the plateau 2-4 hours earlier than the culture activated with 1 $\mu \mathrm{M}$ hormone (Fig 3B).

We also tested if the active loop could be switched-off by removing $\beta$-estradiol from the medium. As shown in Fig $4 \mathrm{~B}$, five hours and two cell duplications after removing the hormone, cells retained nearly $70 \%$ of the $\beta$-galacosidase activity. A new reinoculation and eight more hours were needed to reduce the $\beta$-galactosidase activity below $10 \%$ of the initial values. The comparison with the switchoff of a galactose-activated GAL1pr::lacZ, by transferring the cells from galactose to glucose, rules-out that the slow inactivation of the loop might be due to the high stability of $\beta$-galactosidase (Fig 4B). One possible explanation for these results is that the residual amounts of estradiol remaining inside the cell were sufficient to maintain the activation of the system. An alternative explanation might be that, once the regulatory loop has been triggered, the system remains epigenetically active without needing additional inputs. In any case, this characteristic of the system makes it suitable for regulating gene expression in those industrial applications requiring the absence of $\beta$ estradiol in the final product. In this study we have tested two new regulation strategies: a transcriptional cascade and a feed back regulatory loop. In both cases we have obtained very low levels of increase in basal activity and considerable levels of induction, especially in the feed back loop. Both systems share a basic feature: the inducer acts on the transactivator simultaneously at two levels: its intrinsic activity and its abundance. We believe that this scheme can be used to improve the regulation capacity of other expression systems, whose regulators produce high basal activity of the target promoters.

\section{Conclusion}

The coordinated control of the expression of an estrogenresponsive transcriptional activator with its intrinsic activation amplifies synergistically the regulatory capacity of the target promoter.

The transcriptional cascade described in this work, composed by a constitutively expressed Gal4-ER-VP16 transactivator and a GAL1pr-driven estrogen receptor, does not increase the basal activity of the ERE-containing target promoter, maintaining the regulation efficiency of the previous system.

The self-induced regulatory loop that we have engineered allows a 250 -fold induction of the regulated gene, without increasing the basal activity of the target promoter. The global regulation efficiency of this feed back loop exceeds the estrogen-induced expression systems that have been previously designed for yeast cells. Its hormone-dependence, more gradual than the one usually exhibited by nuclear receptors, allows intermediate levels of regulation. The loop system does not depend on the specific regulators of the GAL1 promoter, facilitating its adaptation to other eukaryotic environments.

\section{Methods}

\section{Strain and plasmids}

The yeast strains used in this study were W303-1A (MATa ade2-1 can1-100 his3-11, 15 leu2-3,112 trp1-1 ura3-1) [23]

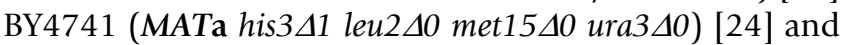
the gal4 $\Delta$ and gal80 $\Delta$ derivative of BY4741 conserved in the EUROSCARF collection. 
All plasmids used in this study were centromeric and are described in Table 1. Plasmid pGAL1-ER was constructed by inserting a $2.1 \mathrm{~kb}$ BamHI DNA fragment from plasmid pP6HEG0 [25], containing the cDNA of human estrogen receptor, into the BamHI site present in p414GAL1 [26], immediately downstream from the GAL1 promoter. Plasmid p414GAL1-GAL4ERVP16 was constructed by inserting a 1,5 kb PCR fragment (oligos ATGAAGCTACTGTCTTCTATCGA and TCACTATAGGGCGAATTGG) from pHCA/GAL4(1-93)ERVP16, encoding the chimeric transactivator GAL4ERVP16 [17], into pGEMT-easy (Promega), generating pGEMTGAL4ERVP16. A $1.5 \mathrm{~kb}$ SpeI fragment from this plasmid was inserted into the SpeI site present in p414GAL1 [26], immediately downstream from the GAL1 promoter. Plasmid p415GAL1-GAL4ERVP16 was constructed by ligating the $2.6 \mathrm{~kb}$ PvulI fragment from p414GAL1-GAL4ERVP16 to the bigest PvulI fragment of pRS415 [27].

Yeast transformation was carried out using standard methods [28]. Transformants were routinely assayed for plasmid stability, by replica-plating after non-selective culturing. Those transformants containing more than one plasmid did not show abnormal levels of plasmid instability.

\section{Culture conditions}

Yeast transformants were cultured at $30^{\circ} \mathrm{C}$ in complete synthetic medium, with $2 \%$ glucose or $2 \%$ galactose as the carbon source [28]. Liquid cultures were incubated in orbital shakers at $120 \mathrm{rpm}$. $\beta$-estradiol (SIGMA E-1024$1 \mathrm{G}$ ) was added when indicated from a $2.5 \mathrm{mM}$ stock solution in ethanol. Equivalent amounts of ethanol were added to control cultures.

\section{$\beta$-galactosidase assays}

$\beta$-galactosidase assays were performed as described previously [29] using a cell-permeabilization method [28]. Activities were calculated as Miller units. Yeast strains containing reporters alone were assayed in the presence of empty expression vectors. Experiments were performed at least three times, although in figures representing timecourse experiments only one is shown. In all cases the replicate produced similar results.

\section{Competing interests}

The University of Seville is currently applying for a patent covering the applications of the results described in this work. Biomedal, SL provided a part of the funding required to develop this work and has signed a licence agreement with the University of Seville, in order to bring to the market some applications of these results.

\section{Authors' contributions}

MJQ carried out most of the experiments and contributed to their design. DM performed some experiments. MAR participated in the design of some experiments and contributed to draft the manuscript. AC contributed to the design of some experiments and, together with SC, conceived the initial approaches. SC performed some experiments, coordinated all the work and drafted the manuscript.

\section{Acknowledgements}

We thank D. Picard for kindly providing plasmid pHCA/GAL4(I93)ERVPI 6 and Benjami Piña for plasmids pVitBx2 and pP6HEG0. This work was supported by the Spanish Ministry for Education and Science (FIT-0 I0000-2003-II 0 and CIT-0 10000-2005-32), by the Andalusian Government (CVI27I) and by Biomedal, SL.

\section{References}

I. Cereghino GPL, Cregg JM: Applications of yeast in biotechnology: protein production and genetic analysis. Current Opinion in Biotechnology 1999, 10:422-427.

2. Gellissen G, Hollenberg CP: Application of yeasts in gene expression studies: a comparison of Saccharomyces cerevisiae, Hansenula polymorpha and Kluyveromyces lactis -- a review. Gene 1997, 190:87-97.

3. Hinnen A, Buxton F, Chaudhuri B, Heim J, Hottiger T, Meyhack B, Pohlig G: Gene expression in recombinant yeast. Bioprocess Technol 1995, 22:121-193.

4. Goeddel DV: Systems for heterologous gene expression. Methods Enzymol 1990, 185:3-7.

5. Hinnen A, Meyhack B, Heim J: Heterologous gene expression in yeast. Biotechnology (Reading, Mass) 1989, 13:193-213.

6. Porro D, Sauer M, Branduardi P, Mattanovich D: Recombinant protein production in yeasts. Mol Biotechnol 2005, 31:245-259.

7. Gellissen G, Melber K, Janowicz ZA, Dahlems UM, Weydemann U, Piontek M, Strasser AW, Hollenberg CP: Heterologous protein production in yeast. Antonie Van Leeuwenhoek 1992, 62:79-93.

8. Mountain HA, Bystrom AS, Larsen JT, Korch C: Four major transcriptional responses in the methionine/threonine biosynthetic pathway of Saccharomyces cerevisiae. Yeast 1991, 7:78I-803.

9. Kramer RA, DeChiara TM, Schaber MD, Hilliker S: Regulated expression of a human interferon gene in yeast: control by phosphate concentration or temperature. Proc Natl Acad Sci U S A I 984, $81: 367-370$.

10. Macreadie IG, Horaitis O, Verkuylen AJ, Savin KW: Improved shuttle vectors for cloning and high-level $\mathrm{Cu}(2+)$-mediated expression of foreign genes in yeast. Gene 1991, 104:107-III.

II. West RW Jr., Yocum RR, Ptashne M: Saccharomyces cerevisiae GALI-GALI 0 divergent promoter region: location and function of the upstream activating sequence UASG. Mol Cell Biol 1984, 4:2467-2478.

12. Yocum RR, Hanley S, West R Jr., Ptashne M: Use of lacZ fusions to delimit regulatory elements of the inducible divergent GALI-GALIO promoter in Saccharomyces cerevisiae. Mol Cell Biol 1984, 4:1985-1998.

13. Fishman GI, Kaplan ML, Buttrick PM: Tetracycline-regulated cardiac gene expression in vivo. J Clin Invest 1994, 93:1864-1868.

14. Belli G, Gari E, Piedrafita L, Aldea M, Herrero E: An activatorl repressor dual system allows tight tetracycline-regulated gene expression in budding yeast. Nucleic Acids Res 1998, 26:942-947.

15. Schneider JC, Guarente L: Vectors for expression of cloned genes in yeast: regulation, overproduction, and underproduction. Methods Enzymol 199I, 194:373-388.

16. Johnston MC M.: Regulation of carbon and phosphate utilization. In The Molecular Biology of the Yeast Saccharomyces Volume 2. Edited by: Jones EWPJRBJR. Cold Spring Harbor, NY, Cold Spring Harbor Laboratory Press; 1992:193-281. 
17. Louvion JF, Havaux-Copf B, Picard D: Fusion of GAL4-VPI6 to a steroid-binding domain provides a tool for gratuitous induction of galactose-responsive genes in yeast. Gene 1993, | 3 |: | 29- I34.

18. Stafford GA, Morse RH: Chromatin remodeling by transcriptional activation domains in a yeast episome. J Biol Chem 1997, 272: II526-II534.

19. Metzger $\mathrm{D}$, White JH, Chambon P: The human oestrogen receptor functions in yeast. Nature 1988, 334:3I-36.

20. Leskinen P, Michelini E, Picard D, Karp M, Virta M: Bioluminescent yeast assays for detecting estrogenic and androgenic activity in different matrices. Chemosphere 2005, 61:259-266.

21. Pierrat B, Heery DM, Lemoine Y, Losson R: Functional analysis of the human estrogen receptor using a phenotypic transactivation assay in yeast. Gene 1992, 1 19:237-245.

22. Arnold SF, Klotz DM, Collins BM, Vonier PM, Guillette LJ Jr., McLachlan JA: Synergistic activation of estrogen receptor with combinations of environmental chemicals. Science 1996, 272: 1489-1492.

23. Rothstein R, Helms $C$, Rosenberg N: Concerted deletions and inversions are caused by mitotic recombination between delta sequences in Saccharomyces cerevisiae. Mol Cell Biol 1987, 7: I I98-1 207.

24. Brachmann CB, Davies A, Cost GJ, Caputo E, Li J, Hieter P, Boeke JD: Designer deletion strains derived from Saccharomyces cerevisiae S288C: a useful set of strains and plasmids for PCRmediated gene disruption and other applications. Yeast 1998, 14:115-132.

25. Green S, Walter P, Kumar V, Krust A, Bornert JM, Argos P, Chambon $P$ : Human oestrogen receptor CDNA: sequence, expression and homology to v-erb-A. Nature 1986, 320:134-139.

26. Mumberg D, Muller R, Funk M: Regulatable promoters of Saccharomyces cerevisiae: comparison of transcriptional activity and their use for heterologous expression. Nucleic Acids Res 1994, 22:5767-5768.

27. Sikorski RS, Hieter P: A system of shuttle vectors and yeast host strains designed for efficient manipulation of DNA in Saccharomyces cerevisiae. Genetics 1989, 122:19-27.

28. Rose MD Winston, F. and Hieter, P.: Methods in Yeast Genetics: A Laboratory Course Manual. Cold Spring Harbor, NY, Cold Sprong Harbor Laboratory Press; 1990.

29. Chavez S, Candau R, Truss M, Beato M: Constitutive repression and nuclear factor I-dependent hormone activation of the mouse mammary tumor virus promoter in Saccharomyces cerevisiae. Mol Cell Biol 1995, 15:6987-6998.

30. Garcia-Reyero N, Grau E, Castillo M, Lopez de Alda MJ, Barcelo D, Pina $B$ : Monitoring of endocrine disruptors in surface waters by the yeast recombinant assay. Environ Toxicol Chem 200I, 20: II52-III5.

\section{Publish with Bio Med Central and every scientist can read your work free of charge}

"BioMed Central will be the most significant development for disseminating the results of biomedical research in our lifetime. "

Sir Paul Nurse, Cancer Research UK

Your research papers will be:

- available free of charge to the entire biomedical community

- peer reviewed and published immediately upon acceptance

- cited in PubMed and archived on PubMed Central

- yours - you keep the copyright

Submit your manuscript here:

http://www.biomedcentral.com/info/publishing_adv.asp
BioMedcentral 